\title{
Um caso de actinomycose visceral primitiva
}

\author{
PELO PROF DR. CARMO LORDY
}

Não é destituido de interesse scientifico e pratico o estudo dos mycetomas principalmente no nosso meio, em que a lavoura e a criação de gado representam o expoente da riqueza productiva nacional.

Poncet, referindo-se especialmente á actinomycose, com sua larga pratica sobre o assumpto, chega á conclusão que 4 vezes sobre 5 esta molestia é observada em pessoas que se dedicam ao cultivo sobretudo dos cereaes ou á criação do gado.

Infelizmente, bem poucos são os casos que se offerecem á observação e que são utilmente estudados; perdendo-se a grande maioria por incuria, por difficuldades diversas ou porque confundidos com os outros granulomas, syphilitico e tuberculoso ou com os blastomas, principalmente com o carcinoma, por causa da dureza lenhosa dos tecidos invadidos commum a ambos.

Entre nós, os poucos casos estudados tiveram sempre como porta de entrada soluções de continuidade da pelle ou das mucosas.

O Dr. Adolpho Lindenberg nas "Dermatoses Brasileiras" cita a observação de Oscar Bulhões e Pedro Deveriano de Magalhães sobre um caso de um pião cearense com lesão actinomycotica inicial tegumentar na parte inferior esquerda do thorax e com invasão consecutiva pulmonar. A autopsia revelou lesões especificas no peritoneo, na região inguino-abdominal esquerda, na pleura, no pulmão esquerdo, no diaphragma, no pericardio, no coração, no figado, baço, rins, meninges e cerebro. Cita ainda as observações de Pacheco Mendes e Gonçalo Muniz, da Bahia e um caso por elle mesmo Estudado de um novo typo de mycetoma (discomyces brasiliensis).

Em 1913 o Prof. Carini apresentou um caso de mycetoma da face, curado com a medição iodica, deixando de classifical-o no capitulo das actinomycoses por não ter notado as terminações em clavas caracteristicas.

O caso de actinomycose, que é objecto de nossa communicação, talvez seja um dos poucos, senão o unico até agora conhecido na literatura nacional, porque se apresentou primitivamente visceral, sem lesão alguma tegumentar ou das mucosas.

O portador J. C., profissional, com 31 annos de idade, faz datar sua molestia de ha 2 e meio annos. Estando numa sua fazenda de criar, foi repentinamente accommettido por um accesso agudo de appendicite, complicado com peritonite localisada. Cerca de um 
mez depois, foi operado pelo Dr. Arnaldo Vieira de Carvalho, tendo sido encontrados restos apenas de processo vermiforme, incluidos num foco purulento, limitado por adherencias de ansas intestinaes. Desde essa época, estabeleceram-se trajectos fistulosos, dando vasão ao puz, coincidindo a diminuição ou suppressão de seu escoamento com o apparecier da febre.

Foram tentadas, sem resultado apreciavel, mais duas intervenções cirurgicas. Ultimamente, sujeitou-se a uma quarta intervenção, por se ter notado na região hepatica producções tumoriformes. Fez-se uma laparotomia de prova, aspirando-se de um destes focos um pouco de material, cujo exame histologico, feito no laboratorio de Anatomia Pathologica da Faculdade de Medicina e Cirurgia de São Paulo, deu o seguinte resultado:

Fixação em sollução a $10 \%$ de formalina, inclusão em paraffina, coloracão pelo hemalumen-eosina e pelo methodo de Gram.

Numerosos pyocytos, quasi todos neutrophilos, raros eosinophilos e restos de cellulas hepaticas degeneradas. Notam-se muitos globulos vermelhos, algumas cellulas hepaticas ainda conservadas $€$ em disposição trabecular, poucas cellulas lymphocitarias e ausencia de gigantocytos, poucas granulações actinomycoticas, rodeadar de cellulas de puz. Principalmente pelo Gram, as colonias se apresentam umas maiores, outras menores, com contornos irregulares, franjados, ás vezes serpiginosas, fixando mais intensamente a côr azul a parte peripherica, do que a central. Com a immersão vê-se uma grande massa de filamentos irregularmente distribuidos e entrelaçados em todos os sentidos. Alguns, principalmente os da peripheria da colonia, mais individualizados e distinctos, se apresentam com o aspecto de bacillos diphtericos.

Ao lado destes, ha outros mais finos, continuando-se na peripheria os de uma especie e os de outra entre as cellulas inflammitorias.

Não se distinguem com nitidez as terminações em clavas caractcristicas. Ha grande abundancia de corpusculos pequeninos, com as dimenseõs e fórma dos communs coccos, entre e ao longo dos filamentos mycelianos, emprestando-lhes assim, uma feição varicosa. Ha tambem fibrina. Com o hemalumen- eosina, as colonias apresentam aspecto caracteristico, notando-se uma degeneração hyolina, diffusa no logar das clavas.

Não se tentou a cultura do discomyse com parte do material enviado, porque se cogitava tratar-se de outro granuloma que não o actinomycetico, e nem posteriormente, por não haver trajecto fistuloso permeavel.

Faltam ou pelo menos não têm a necessaria nitidez as caracteristicas terminações em clava, para este mycetoma entrar no capi- 
tulo das actinomycoses. Interpretadas por muitos autores como elementos degenerados do mycelio, por outros como orgãos de fructificação, por Brumpt como reservas protoplasmicas existindo nas granulações actinomycoticas novas e destinadas a permittir o crescimento do mycelio central, estas formações nem sempre podem marcar o limite exacto entre uma variedede e outra do mycetoma.

A despeito da ausencia ou da pouca nitidez das terminações em clava o nosso caso deve ser capituledo de actinomycose, levando-se tambem em conta o reduzido numero de granulações que o corte histologico offerecia.

Não havendo lesões tegumentares ou das mucosas, desperta interesse saber-se por onde e como o cogumello penetrára na economia.

Das observações reunidas por Lanz na clinica de Kocher, resulta que se deve procurar a origem, approximadamente na metade dos casos de actinomycose abdominal, no appendice ou no segmento ileo-caecal.

Na inocullação do tubo digestivo, diz Poncet, o caecum, o appendice, a ampola rectal representam por sua estase physiologica as melhores condições para o parasita se desenvolver.

Não nos podemos furtar ao desejo de reproduzir as palavras de Aschoff sobre o assumpto: "Fazendo-se abstracção da cavidade bucal, o ponto onde a actinomycose se localiza de preferencia é na região do abdomen, presumindo-se nestes casos que o intestino seja a porta de entrada. Baseando-se nas autopsias e nas intervenções cirurgicas, deve-se principalmente responsabilisar o processo vermiforme, em torno do qual póde-se desenvolver um tecido de granulação neoplasiforme, multiplo, contendo abcessos, isto é, um actinomycose; posteriormente, nem sempre é possivel demonstrar-se a porta de entrada, tanto mais que não é necessario que se produzam lesões da mucosa appendicular. Entre as ansas intestinaes se formam adherencias localizadas semelhantes a tumores com pequenas cavidades purulentas e com paredes amarelladas, com a côr de enxofre. Destes pequenos abcessos partem trajectos fistulosos subtis, escavados na parede intestinal, podendo por ultimo ser perfurada a mucosa. A' primeira vista, si se olhar sómente a parte interna do intestino, póde-se erroneamente julgar-se que exista urna actinomycose primitiva da mucosa. A falta, porém, de ulcera mucosa autonoma, a destruição mais intensa dos estrados parietaes externos $\Theta$ a relação com $o$ abcesso capsulado depõem em favor da invasão secundaria. $O$ processo tende a expandir-se em todas as direç̧ões. Póde-se insinuar nas raizes da veia porta, pro- 
dizindo, com o aspecto de uma thrombo-phlebite purulenta, abcessos hepaticos actinomycoticos extensos".

Este quadro anatomo-pathologico talvez se ajuste em todos os pontos com o caso de nossa observação.

o inicio da molestia, seu caracter essencialmente chronico, suas diversas phases e complicações com trajectos fistulosos, os dados fornecidos pelas sucessivas intervenções cirurgicas reproduzem com grande fidelidade suas linhas principaes.

Resta averiguar como o discomyse penetrára na economia.

Tendo Ponfik demonstrado a identidade anatomo-pathologica desta affecção no homem e no gado, não é para se desprezar, na opinião de Kolle e Hetsch, a possibilidade de transmissão no homem da molestia, vehiculada pelo leite de vacca, nos casos da glandula mammaria estar primaria ou secundariamente infectada.

E' um modo de infecção que talvez se adapte bem ao caso do paciente, que não tinha o habito de mastigar fibras vegetaes, mas que fazia uso e abuso de leite crú.

\section{NOTA}

Tres mezes depois de concluido o presente trabalho, tivemos occasião de vêr o mesmo paciente. Seu estado de saude se achava em franca decadencia.

Apresentava na região hepatica diversas fistulas de paredes encurecidas donde, de quando em vez, escorria liquido purulento e viscoso que aproveitamos para a cultura em meio de Sabouraud, na batata e com resultado sempre negativo (culturas aerebias $e$ aneorobias), embora verificassemos entre lamina e laminula, os caracteres morphologicos typicos do granulo.

Em exames posteriores, precedendo de pouco a morte do paciente, notamos a quasi generalização do mal; nas fezes, no escarro achamos não poucos granulos

Não se praticou a necropsia por motivos puramente sociaes.

\section{BIBLIOGRAPHIA}

J. Ligneres et Spitz - Archives de Parasitologie-T-7.

Poncet et L. Bérard - Archives de Parasitologie-T-8.

E. Brumpt - Precis de Parasitologie.

Adolpho Lindenberg - Dermatoses Brasileiras.

Stephen Artault - Archives de Parasitologie-T-3.

A. Carini - Sopra un caso di micetoma della guancia.

Kolle et Hetsch - La bacteriologie expérimentale.

I. Aschoff - Pathologische Anatomie. 